\title{
Prolonged Grief Related to COVID-19 Deaths: Do We Have to Fear a Steep Rise in Traumatic and Disenfranchised Griefs?
}

\author{
Cyrille Kossigan Kokou-Kpolou \\ University of Picardy Jules Verne
}

\author{
Manuel Fernández-Alcántara \\ University of Alicante
}

\author{
Jude Mary Cénat \\ University of Ottawa
}

\begin{abstract}
The circumstances of coronavirus disease (COVID-19)-related deaths embed multiple traumatic characteristics, alongside several external factors that can disenfranchise individual grief. In this context, severe forms of traumatic distress, guilt, somatization, regret, anger, and unspecific symptoms not yet included in prolonged grief disorder (PGD) criteria could emerge. This article (a) analyzes factors related to bereavement in the context of the COVID-19 pandemic; (b) proposes avenues for meaning-making practices to facilitate individual and collective mourning process; and (c) invites clinicians to pay attention to the traumatic characteristics of COVID-19-related deaths adopting a holistic approach of PGD clinical manifestations, as well as in evaluation and treatment of cases.
\end{abstract}

Keywords: prolonged grief disorder, COVID-19-related deaths, trauma, disenfranchised mourning

On April 30, 2020, barely 4 months after the onset of the coronavirus disease (COVID-19), more than 3.1 million infected patients and 227,000 related deaths have been surpassed (Center for Systems Science and Engineering, 2020). Given the alarming toll of deaths, it is expected that the pandemic will leave behind several million bereaved families and individuals of all ages. For example, in United States, the pessimistic prognostic scenario estimates that 1.238 million White and Black Americans will lose a parent and an estimated 2.381 million will lose at least one grandparent due to the epidemic (Verdery \& Smith-Greenaway, 2020). This overburden of bereavement, without precedent in recent years for an infectious disease, will probably have substantial mental and physical health consequences that will require urgent action in terms of preventive and supportive interventions for bereaved families and individuals in need.

The circumstances surrounding death due to the COVID-19 pandemic embed multiple and indirect traumatic characteristics: (a) the probable multiple deaths for families could lead to "be-

Editor's Note. This commentary received rapid review due to the timesensitive nature of the content. It was reviewed by the Journal Editor.KKT

This article was published Online First June 11, 2020.

(D) Cyrille Kossigan Kokou-Kpolou, Department of Psychology, University of Picardy Jules Verne; (D) Manuel Fernández-Alcántara, Department of Health Psychology, University of Alicante; (D) Jude Mary Cénat, School of Psychology, University of Ottawa.

Correspondence concerning this article should be addressed to Cyrille Kossigan Kokou-Kpolou, Department of Psychology, University of Picardy Jules Verne, 1 Chemin du Thil CS52501, 80025 Amiens Cedex 1, France. E-mail: kkkcyrille@yahoo.fr reavement overload," a distressing overflow of grief that interferes with the capacity to cope; (b) the viral contagiousness of the COVID-19 deprives families of assisting the dying person in their last days of life and performing ritual ceremonies; (c) the social and relational restrictions due to the epidemic prohibit families from visiting their relatives at hospitals or intensive care units, which may elicit or exacerbate feelings of guilt; and (d) in top outbreak-affected countries, funeral ceremonies are forbidden or postponed for up to 6 months after the death (Lazzerini \& Putoto, 2020). If the ceremonies are held, they are restricted to less than 10 individuals; many families and close relatives could not attend them, express their distress, and bid their farewell to their loved ones. For those attending them, the viral onslaught of the disease makes it impossible to come within $1 \mathrm{~m}$ of the coffin, hampering the expression of spontaneous emotion. Under such conditions, most families could get caught in conflicts between what the deceased's wills were and what is currently obtainable. This situation may generate or exacerbate feelings of responsibility and indebtedness guilt.

Furthermore, several factors could lead to the disenfranchisement of the mourning at the individual level: (a) excessive and collective accumulation of deaths could deny recognition of each individual's bereavement; (b) given that the age gradient in COVID-19 mortality mostly concerns the elderly, who are frail and/or suffer from chronic health conditions (Yang et al., 2020), the deep pain and distress felt by bereaved families could be overlooked by society (Fernández-Alcántara \& Zech, 2017; Kokou-Kpolou et al., 2020); (c) the end of home confinement will release accumulated tensions and pressures, with the willingness to rapidly reconnect to social, professional, cultural, and recreational activities, making less available resources of support for the bereaved; (d) low socioeconomic status and precarious life conditions as a consequence of the pandemic (e.g., massive job losses, 
rise in cost of goods and services) will accentuate health care disparities, leading to complications of mourning for many families and individuals. Resultantly, they could feel isolated and their grief-related behaviors could be seen as inadequate compared with those expected in normal situation.

For all these reasons, it stands to argue for a steep rise in traumatic, disenfranchised, and chronic griefs in the aftermath of the epidemic outbreak. These pathological forms of grief response are called prolonged grief disorder (PGD), a new psychiatric category that has been introduced in the 11th edition of the International Classification of Diseases (World Health Organization, 2018). PGD often co-occurs with depression, anxiety, and, under traumatic conditions, posttraumatic stress disorder. The traumatic factors embedded in the circumstances of COVID-19-related deaths need careful attention concerning the comprehensiveness of the manifestations of prolonged grief symptoms in the assessment and treatment of PGD cases in this context. Severe forms of traumatic distress, guilt, somatization, regret, anger, and unspecific symptoms not yet included in PGD criteria could emerge. Research has shown that guilt within 2 year postloss was associated with both prolonged grief and depressive symptoms and predicted both conditions 1 year later ( $\mathrm{Li}$, Tendeiro, \& Stroebe, 2019). Furthermore, it has been shown that guilt is one of the main predictors-more than core PGD symptoms per se (such as persistent yearning or preoccupation about the deceased)- of the severity of somatization after the loss (Kokou-Kpolou, Mbassa Menick, Moukouta, \& Ngameni, 2018).

Empirical knowledge in bereavement, culminating with the introduction of PGD in psychiatric classification systems, serves as initial guidelines for clinical assistance for families and individuals afflicted by COVID-19-related deaths. Awareness of each country's contextual requirements in response to the pandemic, and of the specific traumatic elements embedded in the circumstances of these deaths, will help, nonetheless, to avoid pathologizing all at-risk bereaved persons. For example, the time criterion for PGD diagnosis will need notable nuances. Following PGD guidelines, what are the actionable propositions?

- Affected countries should implement national mental health programs that address bereavement issues and include well-trained health care professionals.

- Given the social and relational restrictions due to the pandemic, there is urgent need to develop and disseminate Internet-based PGD interventions (Eisma, Boelen, \& Lenferink, 2020). However, assistance to families and individuals with limited resources is needed to ensure that digital health care disparities are not exacerbated.

- Priority should be given to evidence-based and culturally sensitive interventions. The higher mortality among Black Americans, for example, shows the need for culturally sensitive competencies to meet their needs and representations of death and mourning.

- When the COVID-19 pandemic is over, collective meaning-making practices, at the national level and in locations affected by the pandemic, will be important to free up collective and individual resources, as well as to support resilience in response to death loss endured.

- Finally, countries could take advantage of this pandemic to put in place national bereavement response plans for collective traumatic deaths. This could provide valuable insights for health care professionals, who are not always trained to deal with bereavement suffering.

\section{References}

Center for Systems Science and Engineering. (2020). COVID-19 Dashboard by the Center for Systems Science and Engineering (CSSE) at Johns Hopkins University (JHU). Retrieved April 30, 2020, from https:// gisanddata.maps.arcgis.com/apps/opsdashboard/index.html\#/bda7594 740fd40299423467b48e9ecf6

Eisma, M. C., Boelen, P. A., \& Lenferink, L. I. M. (2020). Prolonged grief disorder following the coronavirus (COVID-19) pandemic. Psychiatry Research, 288, 113031. http://dx.doi.org/10.1016/j.psychres.2020 .113031

Fernández-Alcántara, M., \& Zech, E. (2017). One or multiple complicated grief(s)? The role of kinship on grief reactions. Clinical Psychological Science, 5, 851-857. http://dx.doi.org/10.1177/2167702617707291

Kokou-Kpolou, K. C., Jumageldinov, A., Park, S., Nieuviarts, N., Khales, C., \& Cénat, J. (2020). Differential associations of coping strategies with grief and depression in young adults: The role of cause of death and relationship to the deceased. Journal of Social and Clinical Psychology, 39, 187-210.

Kokou-Kpolou, K. C., Mbassa Menick, D., Moukouta, C. S., \& Ngameni, E. G. (2018). Étude du lien entre deuil, dépression et troubles somatiques auprès d'une population d'immigrés ouest-africains en Europe [Association between mourning, depression and somatic symptoms: Results from a sample of West African immigrants in Europe]. Revue Européenne des Migrations Internationales, 34, 159-186. http://dx.doi.org/10 4000/remi. 10930

Lazzerini, M., \& Putoto, G. (2020). COVID-19 in Italy: Momentous decisions and many uncertainties. Lancet Global Health, 8, e641-e642. http://dx.doi.org/10.1016/S2214-109X(20)30110-8

Li, J., Tendeiro, J. N., \& Stroebe, M. (2019). Guilt in bereavement: Its relationship with complicated grief and depression. International Journal of Psychology, 54, 454-461. http://dx.doi.org/10.1002/ijop.12483

Verdery, A. M., \& Smith-Greenaway, E. (2020). COVID-19 and family bereavement in the United States. Applied Demography, 32(1), 1-20. Retrieved from http://www.populationassociation.org/wp-content/ uploads/CAD_SpecialEdition_COVID19_March2020.pdf\#page $=3$

World Health Organization. (2018). International statistical classification of diseases and related health problems. Geneva, Switzerland: Author.

Yang, J., Zheng, Y., Gou, X., Pu, K., Chen, Z., Guo, Q., . . . Zhou, Y. (2020). Prevalence of comorbidities and its effects in patients infected with SARS-CoV-2: A systematic review and meta-analysis. International Journal of Infectious Diseases, 94, 91-95. http://dx.doi.org/10 $.1016 /$ j.ijid.2020.03.017

Received April 30, 2020

Revision received May 14, 2020

Accepted May 18, 2020 